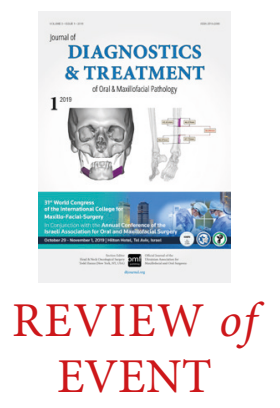

\section{Visiting Professorship in Jacksonville-Leo and Hilary Cheng: Life-saving Surgeries on the Waves March, 2018}
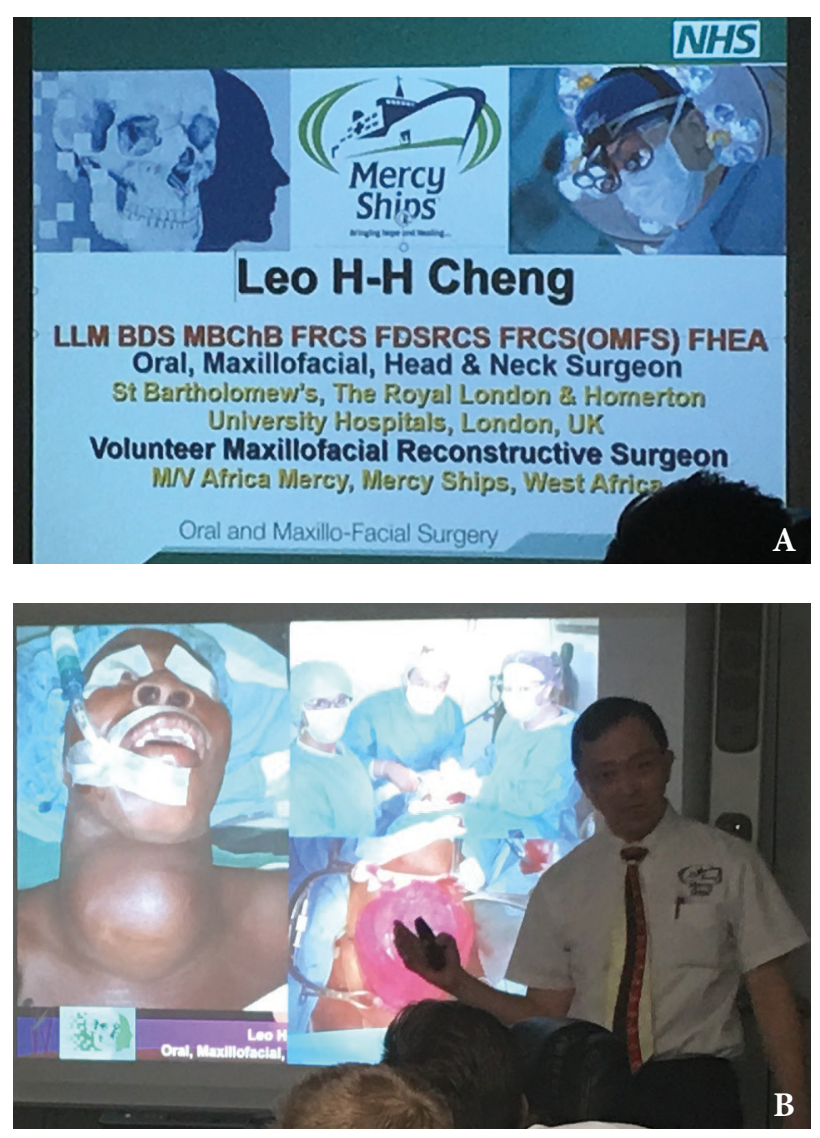

FIGURE. (A, B) Lecture of Dr. Leo and Hilary Cheng in Oral \& Maxillofacial Surgery Department, University of Florida College of Medicine, Jacksonville, FL, USA; March, 2018.
"The purpose of human life is to serve, and to show compassion and the will to help others." - Albert Schweitzer

Alsatian theologian, organist, writer, humanitarian, philosopher, \& physician

$\mathrm{D}$ r. Leo H-H Cheng and his wife Hilary Cheng burned a fire in our hearts. Fire of the great need to help others in any possible way. And we, as the surgeons, can do this not only on the land in our surgical departments and hospitals, but on the waves as well. During the annual trips, Dr. Cheng works on board the world's largest nongovernmental hospital ship, the Africa Mercy [1]. Mercy Ships are the places in which the physicians and nurses from different counties are giving their best to the poorest people on the continent [1]. But Mercy Ships doesn't just take doctors and nurses - the ship is a small city, with cooks, teachers, receptionists, mechanics, IT specialists, engineers and cleaners [2]. Dr. Cheng performs a lot of the life-saving surgeries in a head and neck area together with colleagues from neighboring specialties.

The example of Dr. Leo and Hilary Cheng during their lectureship program in Jacksonville (Fig) gave us so many inspiration to support others around the globe with our surgical skills. And no matter how small or big amount of help each of us can bring into that world. Mercy Ships are the precise places in which our help will bring so many happines for needy patients.

"Miraculous work of the Mercy Ships." -Leo H-H Cheng

Ievgen I. Fesenko, PhD, Assistant Professor Kyiv, Ukraine i.i.fesenko@dtjournal.org Instagram: dr_eugenfesenko

\section{References}

1. Mercy Ships. Available at: http://lemonchase.com/mercyships/ Access January 10, 2019.

2. Meet the Crew. Available at: https://www.mercyships.org. uk/serve-onboard/meet-the-crew/ Access January 12, 2019. 